\title{
A High-Temperature, "Volume-Type", ECR Ion Source for RIB Generation"
}

\author{
G. D. Alton, T. Zhang ${ }^{\dagger}$, Y. Liu, C. A. Reed ${ }^{\ddagger}$, C. Williams ${ }^{\ddagger}$, \\ Oak Ridge National Laboratory, P. O. Box 2008, Oak Ridge, TN 38731-6368 USA
}

\begin{abstract}
A high temperature, low-charge-state, "volume-type" source has been designed for use in the nuclear physics and nuclear astrophysics research radioactive ion beam (RIB) programs at the Holifield Radioactive Ion beam Facility (HRIBF). The source utilizes electromagnetic coils to generate a large and uniformly distributed central magnetic field with magnitude $(875 \mathrm{G})$ chosen to be in electron-cyclotron-resonance (ECR) with singlefrequency $(2.45 \mathrm{GHz})$ microwave radiation. Among the features of the source include: a variable mirror-ratio at ion extraction as required for optimizing low-charge state ion beam generation; a right-hand, circularly-polarized $R F$ injection system to overcome the relatively-low, cutoff-density, $\left(n_{c}=7.4 \times 10^{10} / \mathrm{cm}^{3}\right)$ associated with the use of $2.45 \mathrm{GHz}$ microwave radiation; and a high temperature, Ir- or Re-coated-Ta plasma chamber to reduce the residence times of radioactive species that are adsorbed on the walls of the chamber. No provisions are made for radial plasma confinement due to the sensitivity of permanent magnets to degradation by the large fluxes of neutrons incumbent during target irradiation, routinely used for this purpose. Aspects of the design features of the source are described in this report.
\end{abstract}

\section{INTRODUCTION}

Chemically active species, diffused from target materials for use at ISOL-based radioactive ion beam (RIB) research facilities, often arrive at the ionization chamber of the source in a variety of molecular forms. Since hotcathode sources, such as the CERN-ISOLDE electronbeam-plasma ion source, presently used at the HRIBF, do not efficiently dissociate and ionize the atomic constituents of such carriers, the species of interest are often distributed in a variety of side-band ion beams with different masses and thereby, their intensities are diluted. Since intensity is at a premium for nuclear physics and astrophysics research with RIBs, it is important to concentrate the species of interest into a single masschannel. ECR ion sources are particularly effective means for simultaneousiy dissociating molecules and ionizing their atomic constituents. While these sources are most

Research sponsored by the U.S. Department of energy under contract De-AC05-960R22464 with Lockheed Martin Energy Research Corp.

'On leave from China Institute of Atomic Energy (CLAE), P. O. Box 275(3), Beijing 102413, China.

'Oak Ridge Institute of Science and Engineering (ORISE), Oak Ridge, TN 37831-6368. frequently used for generating multiply charged ion beams for which the plasma confining magnetic field must be optimized at high field values, the magnetic field can also be customized to accentuate low charge-state ion beam generation as required for radioactive ion beam (RIB) generation at the HRIBF. The present source design is predicated on recent advances in ECR ion source technology effected by designing the magnetic field so that the central magnetic field is uniformly distributed over a large volume with magnitude chosen to be resonant with $2.45 \mathrm{GHz}$ microwave radiation [1-4]. By enlarging the ECR zones, the performances (molecular dissociation and ionization efficiencies) can be enhanced over those of conventional minimum- $B$ geometry sources.

In this report, we briefly describe, the mechanical design features, magnetic field design attributes, ion extraction optics and the $R F$ injection system for the source.

\section{MECHANICAL DESIGN FEATURES}

An isometric representation of the source is illustrated in Fig. 1. The source assembly consists of a tubular Ta plasma chamber (inner diameter: $75 \mathrm{~mm}$; length: 265 $\mathrm{mm}$ ) to which is welded tubular Ta production beam entry and target chambers, positioned at right angles with respect to the plasma chamber axis. The production beam will pass through the center of the plasma chamber, at a right-angle with respect to the axis of symmetry of the source, where it will interact with target material, located in a target chamber diametrically opposed to the entry port, before coming to rest in a C-beam-stop. The plasma and target chambers will be coated with Ir or Re because of their low enthalpies for adsorption of many electronegative members of the periodic chart to reduce the residence times of RIB species that strike the plasma chamber walls. The end flanges of the plasma chamber, production beam entry port, and target chamber ports will be made of stainless steel, fusion-bonded to Ta. These flanges will be equipped with knife-edge-type metal-tometal vacuum seals. Target materials will be heated to temperatures exceeding $2000{ }^{\circ} \mathrm{C}$ by resistively heating a Ta-heater that surrounds the target material reservoir. The plasma chamber will be independently heated up to $\sim 1500{ }^{\circ} \mathrm{C}$ by $\mathrm{Ta}$ wrap-around heaters. The large conductance target chamber is close-coupled to the plasma chamber of the source in order to efficiently transport radioactive species to the plasma chamber of the source.

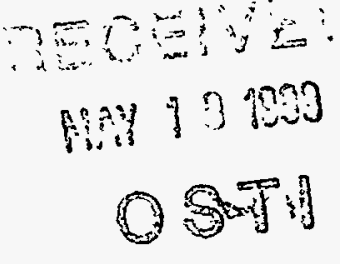

The submitted manuscript has been authored by a contractor of the U.S. GE-AC05-960R22464. Accordingly, the U.S. Government retains a nonexclusive royalty-free license to publish or reproduce the published form of this contribution, or allow others to do so, for U.S. Government
purposes." 


\section{DISCLAIMER}

This report was prepared as an account of work sponsored by an agency of the United States Government. Neither the United States Government nor any agency thereof, nor any of their employees, make any warranty, express or implied, or assumes any legal liability or responsibility for the accuracy, completeness, or usefuiness of any information, apparatus, product, or process disclosed, or represents that its use would not infringe privately owned rights. Reference herein to any specific commercial product, process, or service by trade name, trademark, manufacturer, or otherwise does not necessarily constitute or imply its endorsement, recommendation, or favoring by the United States Government or any agency thereof. The views and

- opinions of authors expressed herein do not necessarily state or reflect those of the United States Government or any agency thereof. 


\section{DISCLAIMER}

Portions of this document may be illegible in electronic image products. Images are produced from the best available original document. 


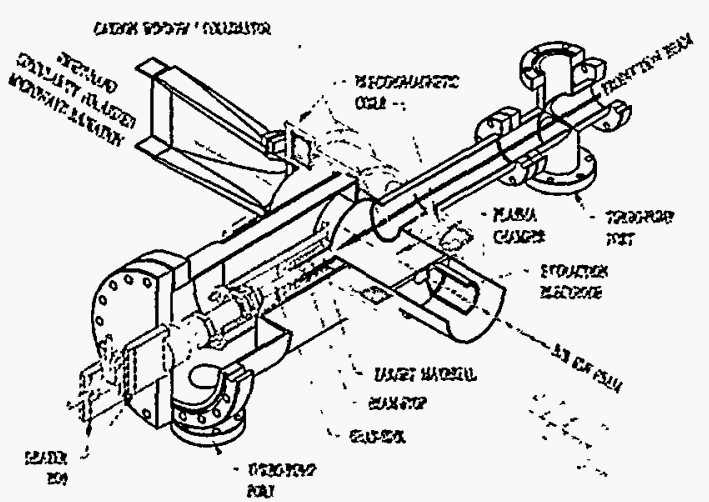

FIG. 1. Schematic representation of the high-temperature, lowcharge-state ECR source

\section{MAGNETIC FIELD DESIGN}

For the source to perform according to the underlying principals, it is quintessential that the central field region be uniformly distributed (flat) along the axis of symmetry of the source with magnitude commensurate with the value required for excitation with singlefrequency, $2.45 \mathrm{GHz}$ microwave radiation $\left(\mathrm{B}_{\mathrm{ECR}}=875 \mathrm{G}\right)$. The magnetic-field distribution, shown in Fig. 2, was computationally designed to achieve this objective by use of the simulation code Poisson [5]. The required flat central resonant field region is generated with two sets of primary and trim coil systems (inner coil diameters: $\Phi 122$ $\mathrm{mm}$ ) located at each end of the plasma chamber; each coil system is housed in a magnetic flux return yoke (outer diameter: $\Phi 254 \mathrm{~mm}$ ). The axial magnetic field is designed with a fixed, high mirror ratio at the $R F$ injection end and a variable mirror ratio at the extraction

TABLE 2. Magnetic field intensity and uniformity values for the magnetic field distribution

\begin{tabular}{cccccccccc}
\hline $\begin{array}{c}\text { Peak Value: } \\
\text { Extraction end } \\
(\mathbf{G})\end{array}$ & $\begin{array}{c}\text { Peak Value: } \\
\text { RF injection } \\
\text { end (G) }\end{array}$ & $\begin{array}{c}\text { Flat-B } \\
\text { Region (cm) }\end{array}$ & $\begin{array}{c}\text { Flat-B } \\
\text { Uniformity } \\
(\%)\end{array}$ & $\begin{array}{c}\text { Bmax } \\
(G)\end{array}$ & $\begin{array}{c}\text { Bmin } \\
(G)\end{array}$ & $\begin{array}{c}\text { Primary Coil: RF } \\
\text { injection end } \\
\text { (A.Turns) }\end{array}$ & $\begin{array}{c}\text { Primary coil: } \\
\text { Extraction end } \\
\text { (A.Tums) }\end{array}$ & $\begin{array}{c}\text { Trim Coil: RF } \\
\text { injection End } \\
\text { (A.Tums) }\end{array}$ & $\begin{array}{c}\text { Trim Coil : } \\
\text { Extraction End } \\
\text { (A.Tums) }\end{array}$ \\
\hline 968 & 1646 & 8.5 & \pm 1.0 & 884 & 867 & 18700 & 7700 & 2500 & -2800 \\
1051 & 1644 & 8.0 & \pm 1.0 & 883 & 866 & 18650 & 8810 & 2000 & -2800 \\
1146 & 1638 & 7.5 & \pm 1.0 & 884 & 866 & 18550 & 10030 & 1520 & -2800 \\
1466 & 1600 & 7.5 & \pm 1.3 & 886 & 863 & 18170 & 15500 & -1540 & -2900 \\
1572 & 1572 & 7.5 & \pm 1.0 & 884 & 866 & 17800 & 17800 & -2900 & -2900 \\
\hline
\end{tabular}

\section{EXTRACTION OPTICS}

In order to ensure beams with good transport properties and minimise aberration effects imparted to the beam during extraction, a series of simulation design studies for space charge limited extraction from the source were performed with the simulation code, PBGuns [6]. The following formula was used initially in choosing initial values for certain parameters such as the extraction gap, $d$, radius, $r_{c}$, of the aperture in the first extraction electrode (cathode), and extraction voltage, $V$, for spacecharge limited flow through the system [7]: end of the source, as required to optimize the efficiencies for dissociation of molecular carriers and ionization of their atomic constituents. While the mirror coils serve to confine the plasma in the axial direction, no analogous provisions are made for radial plasma confinement due to the sensitivity of permanent magnets to degradation by the large fluxes of neutrons incumbent during target irradiation, routinely used for this purpose. As noted, the field is designed to be uniform over a length of $\sim 75 \mathrm{~mm}$. In order to produce a central field distribution with the desired uniformity, high permeability, cylindrical geometry $\mathrm{Fe}$ shunts, located between the trim coils, are also required. The parameters of the magnetic field system are listed in Tables 1 and 2.

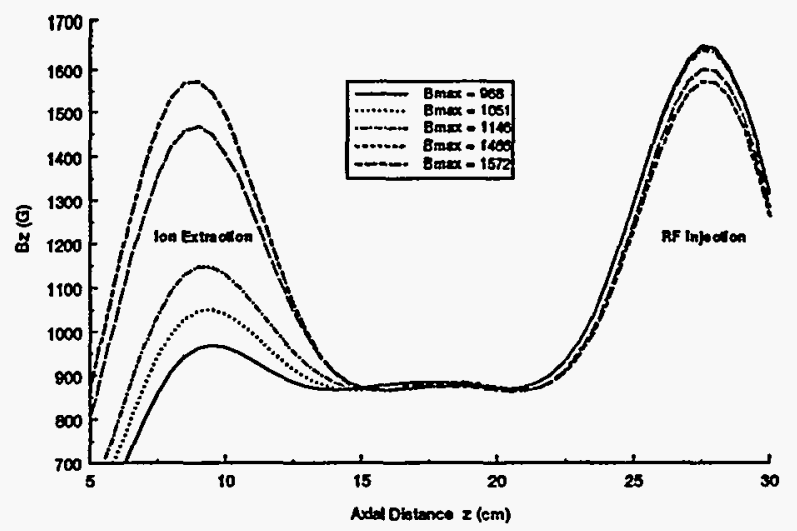

FIG 2. Axial magnetic field profile for the low-charge-state ECR ion source.

TABLE 1. Mirror ratios of the axial magnetic field

\begin{tabular}{ll}
\hline RF injection end : & $\mathrm{B}_{\max } / \mathrm{B}_{\mathrm{BCR}}=\sim 2 / 1$ \\
Ion extraction end: & $\mathrm{B}_{\mathrm{mxx}} / \mathrm{B}_{\mathrm{ECO}}=1.1 / 1$ to $1.8 / 1$ \\
\hline
\end{tabular}


of beam transport of a $1.62 \mathrm{~mA}$ beam of ${ }^{* 0} \mathrm{Ar}^{+}$through the three electrode extraction system is shown in Fig. 3.

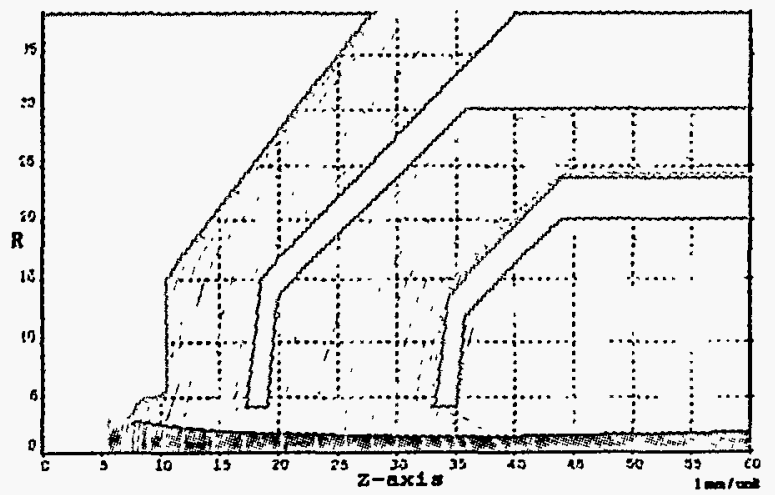

FIG. 3. The beam profile of a $1.62 \mathrm{~mA}^{\circ} \mathrm{Ar}^{+}$beam extracted from the "volume-type" ECR ion source

From the figure, it can be seen that the spherical-sector plasma-electrode plays an important role in focusing the beam; the field gradients between the focus electrode and first and second extraction electrodes form a smooth extraction field, resulting in transportable beams with good emittance characteristics. This electrode system can also be used for extraction and transport of highly spacecharge-dominated proton beams. In this situation, only the first electrode is used for extraction; the second electrode is biased negatively by $\sim-1 \mathrm{kV}$ to repel secondary electrons generated by ion impact with beam transport components and residual gas atoms that would otherwise be accelerated to the source. The result of these studies suggest that a $200 \mathrm{~mA}$ proton beam can be extracted from an 8-mm-diameter aperture at $55 \mathrm{kV}$. The $R M S$ emittance for this case was found to be: $\varepsilon_{\mathrm{n}}=\sim 5 \times 10^{-2}$ $\pi \mathrm{mm}$ mrad.

TABLE 3. Simulation results for different species extracted from the "volume-type" ECR ion source

\begin{tabular}{ccccc}
\hline Species & $\begin{array}{c}\text { Intensity } \\
(\mathrm{mA})\end{array}$ & $\begin{array}{c}\text { RMS Emittance } \\
(\pi \mathrm{mm} \text { mrad })\end{array}$ & $\begin{array}{c}\mathrm{V}_{\mathrm{ezl}} \\
(\mathrm{kV})\end{array}$ & $\begin{array}{c}\mathrm{V}_{\mathrm{en} 2} \\
(\mathrm{kV})\end{array}$ \\
\hline${ }^{12} \mathrm{C}$ & 1.62 & $4.549 \times 10^{-4}$ & 7.0 & 20 \\
${ }^{18} \mathrm{O}$ & 1.62 & $3.995 \times 10^{-4}$ & 8.0 & 20 \\
${ }^{\infty} \mathrm{Ar}$ & 1.62 & $4.768 \times 10^{-4}$ & 8.0 & 20 \\
${ }^{84} \mathrm{Kr}$ & 1.62 & $2.978 \times 10^{-4}$ & 10.6 & 20 \\
${ }^{132} \mathrm{Xe}$ & 1.62 & $4.567 \times 10^{-4}$ & 12.8 & 20 \\
${ }^{200} \mathrm{Bi}$ & 1.13 & $6.149 \times 10^{-4}$ & 12.0 & 20 \\
\hline
\end{tabular}

\section{RF INJECTION SYSTEM}

The microwave $R F$ injection system features a right-hand circular polarizer to avoid the relatively-low cut-off density limit $\left(\mathrm{n}_{\mathrm{c}}=7.4 \times 10^{10} / \mathrm{cm}^{3}\right)$ associated with the use of $2.45 \mathrm{GHz}$ microwave radiation. The microwave injection system consists of a $2.45 \mathrm{GHz}, 2 \mathrm{~kW}$ magnetron power supply, circulator, directional coupler, WR-340 wave guide, stub-tuner, a right-hand circular polarizer, a rectangular-to-circular wave-guide converter and a circular plasma chamber. The microwave radiation travels along the rectangular wave-guide in the $\mathrm{TE}_{10}$ mode; this mode is then converted to a $\mathrm{TE}_{11}$ mode in a rectangular- to-circular transition wave-guide section. The finite element code ANSYS [8] was used in determining the length of the converter that would minimize reflected power. Fig. 4 illustrates the dependence of reflected power on the length of the rectangular-to-circular transition section. The results of this studies also show that the forward power possesses the frequency independent character of the $R F$ injection system. Fig. 5 shows that the electric field distribution is concentrated near the axis of the uniformly distributed magnetic field, in keeping with efficient coupling of the $R F$ power to the plasma.

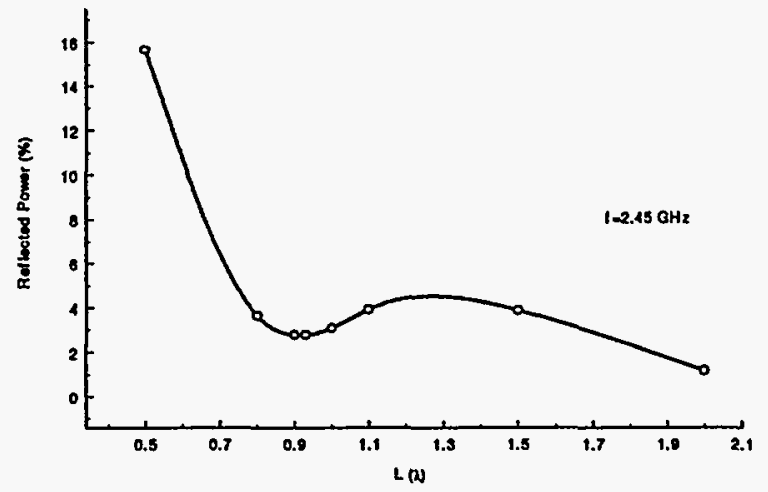

FIG. 4. Reflected power versus frequency for the RF injection

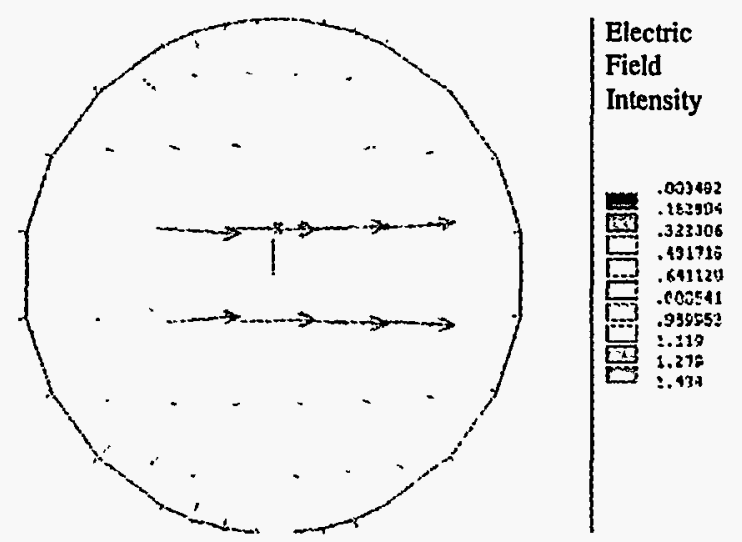

FIG. 5. The electric field distribution in the plasma chamber

\section{REFERENCES}

1. G. D. Alton and D. N. Smithe, Rev. Sci. Instrum. 65 (1994) 775.

2. G. D. Alton, in Proceedings of the $14^{4}$ International Conference on Cyclotrons and their Applications, edited by J. C. Comell, Capetown, South Africa, 8-13 October, 1994, (World Scientific, Singapore), p. 362.

3. G. D. Alton, F. W. Meyer, Y. Liu, J. R. Beene, D. Tucker, Rev. Sci. Instrum. 69 (1998) 2305.

4. A. Heinen, et. al., Rev. Sci. Instrum. 69 (1998) 729.

5. Poisson is a two-dimensional code for the simulation of magnetic fields developed at the Los Alamos National Laboratory, LA-UR87-126(1987).

6. PBGuns is an electron/ion optics simulation code, developed by Thunderbind Simulations, Garland, TX.

7. G. D. Alton, Applied Alomic Collision Physics, ed. S. Datz, Vol. 4, Ch. 2, Academic Press, New York, 1983, pp163.

8. ANSYS is a finite element code developed by ANSY Inc. Canonsburg, PA. 